\title{
Which aortic valve prosthesis I would implant on myself?
}

\author{
Gabriele Di Giammarco, MD, and Daniele Marinelli, MD
}

\author{
From the Department of Cardiac Surgery, Università degli Studi “G. D'Annunzio” Chieti-Pescara, Chieti, Italy. \\ Disclosures: Authors have nothing to disclose with regard to commercial support. \\ Received for publication Aug 22, 2017; revisions received Sept 1, 2017; accepted for publication Sept 12, 2017; \\ available ahead of print Oct 10, 2017. \\ Address for reprints: Gabriele Di Giammarco, MD, Università degli Studi “G. D’Annunzio Chieti-Pescara, Via \\ dei Vestini, SNC 66100, Chieti, Italy (E-mail: gabrieledigiammarco57@gmail.com). \\ J Thorac Cardiovasc Surg 2018;155:548 \\ $0022-5223 / \$ 36.00$ \\ Copyright $(2) 2017$ by The American Association for Thoracic Surgery \\ https://doi.org/10.1016/j.jtcvs.2017.09.056
}

In reading the article by Schnittman and colleagues ${ }^{1}$ in this issue of the Journal, the first question that came to our minds was, "Which prosthesis would I choose to replace my aortic valve?"

This question comes to the surgeon's mind whenever he or she talks to a young patient and tries to explain, in the most understandable words, the potential benefits and disadvantages of a biologic versus a mechanical prosthesis. This discussion, as Schnittman and colleagues ${ }^{1}$ correctly state, is conducted without reasonable evidence from the literature that can guide surgeons and patients in their decision making. The crucial and most important aspect of the article of Schnittman and colleagues ${ }^{1}$ is to give answers to this question.

In the recent (2017) American Heart Association and American College of Cardiology focused update of their 2014 guideline for the management of patients with valvular heart disease, patients' preference to avoid longterm oral anticoagulation required for mechanical valves is confirmed as a class I recommendation. ${ }^{2}$

The crucial distinctions that factor into the choice between a bioprosthesis and a mechanical valve are the risk of reintervention seen with the former and the need for an indefinite oral anticoagulant therapy and its potential complications associated with the latter. Moreover, the need for oral anticoagulation is the most disabling aspect of the use of mechanical prostheses, especially in young patients, as represented in this study of Schnittman and colleagues.

Another fundamental distinction with a mechanical prosthesis is the necessity to change lifestyle (pregnancy, sport, work activity, continuous monitoring of anticoagulation therapy, and so on). Late after aortic valve replacement with a mechanical prosthesis, patients have been reported to have a worse physical component score of their 12Item Short Form Survey health status quality of life instrument relative to those who received a bioprosthesis. ${ }^{3}$ In addition, those with a mechanical valve had a higher negative perception of their ability to work, advance in their career, and receive an appropriate income, with an odds ratio of 2.2. The rate of disability was significantly higher bioprostheses.

\section{References}

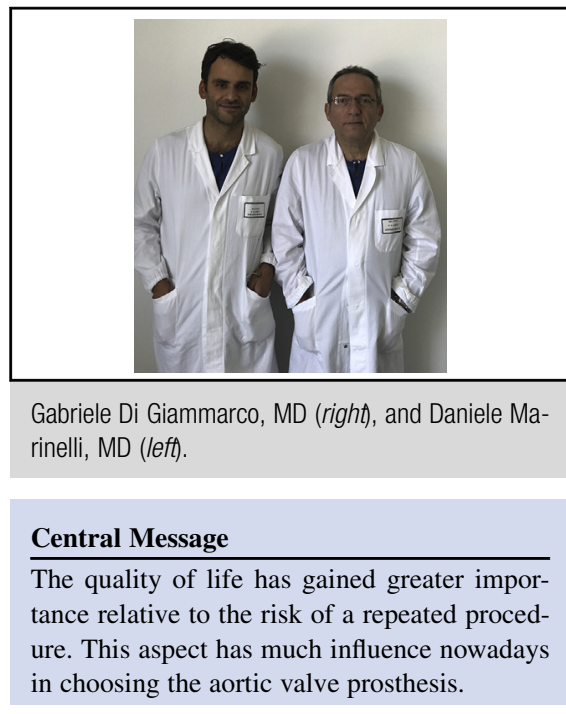

See Article page 539.

among patients who underwent an aortic valve replacement with a mechanical valve than among those who received a bioprosthetic valve, with an odds ratio of 2.8 .

Another interesting issue is compliance with oral anticoagulation therapy. One of the most important risk factors for low therapeutic adherence to oral anticoagulation is age younger than 55 years. ${ }^{4}$ Other considerations are also important in the choice of prosthesis, especially the recent availability of transcatheter treatment of degenerated

The article by Schnittman and colleagues ${ }^{1}$ contributes to illuminating the darkness and decreasing the doubts of surgeons and patients about the choice of prosthesis. This information may inform the choice, with the target of ensuring the optimal quality of life for the patient.

1. Schnittman S, Adams DH, Itagaki S, Toyoda N, Egorova NN, Chikwe J. Bioprosthetic aortic valve replacement: revisiting prosthesis choice in patients younger than 50 years old. J Thorac Cardiovasc Surg. 2018;155:539-47.e9.

2. Nishimura RA, Otto CM, Bonow RO, Carabello BA, Erwin JP III, Fleisher LA, et al. 2017 AHA/ACC focused update of the 2014 AHA/ACC guideline for the management of patients with valvular heart disease: a report of the American College of Cardiology/American Heart Association Task Force on Clinical Practice Guidelines. Circulation. 2017;135:e1159-95.

3. Ruel M, Kulik A, Lam BK, Rubens FD, Hendry PJ, Masters RG, et al. Long-term outcomes of valve replacement with modern prostheses in young adults. Eur J Cardiothorac Surg. 2005;27:425-33; discussion 433.

4. Johnston JA, Cluxton RJ Jr, Heaton PC, Guo JJ, Moomaw CJ, Eckman MH. Predictors of warfarin use among Ohio Medicaid patients with new-onset nonvalvular atrial fibrillation. Arch Intern Med. 2003;163:1705-10. 